\title{
Exposure to the Law: Accountability and Its Impact on Street-level Bureaucracy
}

\author{
Mark Murphy* and Paul Skillen** \\ *School of Education, University of Glasgow \\ E-mail: mark.murphy.2@glasgow.ac.uk \\ **Faculty of Education and Children's Services, University of Chester \\ E-mail:p.skillen@chester.ac.uk
}

Little research has been conducted exploring the relationship between public-sector accountability and the law. This is a significant oversight given the potential for this relationship to cause unintended consequences around issues of liability, especially in the context of a growing litigation culture. The purpose of the current research is to explore this relationship, using qualitative studies of public-sector professionals in England. The findings of the study suggest that increasing emphasis on accountability has led to a growing magnification of legal risk in the public sector, with consequences for the ways public-sector professionals perceive their relationships with the public.

Keywords: Accountability, bureaucracy, public sector, litigation, evidence.

\section{Introduction}

The bureaucracy surrounding accountability has altered the landscape of public services due to its increasing growth over recent decades. In particular, the implementation of quality assurance mechanisms - audit, inspection, performance indicators, evaluation - has opened up the public sector to ever greater scrutiny (Travers, 2007). Professions such as education, health and social work are under increasing pressure to evidence accountability to the public and the public purse, with the mechanisms of this bureaucracy designed to increase formal levels of accountability to the state while also making the public sector more accountable to the public via marketisation and the development of a consumer culture.

This trend towards ever-increasing accountability is part of a broader agenda of regulation in relation to public-sector reform initiatives (James, 2005; Bundfred, 2006). Given its political importance, it is inevitable that debates have developed over the usefulness of such a bureaucratic apparatus. Increasingly, evidence suggests that these state bureaucratic systems, rather than alleviate issues associated with a lack of public accountability, have unwittingly managed to help facilitate their development in the first place (Ossege, 2012; Mendez and Bachtler, 2011; Liff, 2014). The evidence from a range of studies indicates that accountability can be a 'double-edged sword' (Papadapoulos, 2010: 1032), with a number of unintended consequences arising from the reforms, including risk avoidance (Papadapoulos, 2010: 1032) and what Bovens calls the 'accountability trap' (2010: 958), a trap in which public servants achieve success in meeting accountability targets, yet are not 'necessarily performing better in the real world of policy-making and public service delivery' (Bovens, 2010: 958). 
Problems associated with political accountability suggest it deserves its 'tricky' reputation (Barberis, 1998: 451), a reputation no more pronounced than in the context of public-sector regulation. Attempts to manage and control outcomes via mechanisms such as audit and inspection face numerous difficulties, with the gap between the ideal and reality (Bovens, 2010) often too wide to deliver satisfactory outcomes. This gulf means that the consequences of accountability are often unintended and unwanted, sometimes creating more problems than they solve. Accountability arrangements, for all their value, 'do not necessarily produce better government' (Bovens, 2010: 958).

Accountability is also tricky because it is subject to numerous definitions, depending on context. For example, accountability as a set of mechanisms used by the state to regulate the public sector is distinct from the public's perspective of accountability as bringing professions and professionals to account. Procedures are also different for the public and the state: members of the public can hold professionals to account by recourse to litigation, while the state and its regulatory agencies have access to sanctions (e.g., withholding of resources, fitness to practice procedures). On top of that, the notion of accountability now encompasses numerous other understandings that have taken accountability far from its 'core' - the relationship between citizens and holders of public office (Mulgan, 2000: 556).

The problems encountered when taking people and organisations to account can be seen as a reflection of more troubling issues associated with regulatory regimes. Attempts to regulate professional spaces of one kind or another are fraught with logistical, technical and temporal issues. Efforts to ensure compliance can often be a thankless task, thanks in part to the existence of numerous other regulatory mechanisms - for example, norms, value systems, the market - that deny political accountability a monopoly on social control (Parker, 2008). The plurality of regulatory systems also confuses the meansends rationality embedded in political accountability frameworks, to such an extent that associations between cause and effect become impossible to verify.

One increasingly evident example of this regulatory complexity is the prevalence of legal forms of accountability in the public sector. Recent years have seen the spread of an American-style litigation culture in the UK, with members of the public increasingly seeking recourse to the law to appeal or complain, or to achieve compensation (Allsop and Jones, 2008). The increasing tendency of people to resort to litigation suggests that recourse to the law is seen as a more immediate form of taking public services to account. Numerous aspects of public-sector work have been affected by the spread of a litigation culture, with the health, police and education sectors seeing steady rises in the number of lawsuits (Furedi and Bristow, 2012).

Given this burgeoning intersection between law and public-sector accountability, it is surprising that the relationship between political and legal forms of regulation has not been explored in any detail. Using qualitative case studies of teachers, nurses and social workers in England (via a combination of interviews and focus groups), the current study sought to plug this gap in the literature by exploring the ways in which the regulatory functions of the bureaucracy of accountability negotiate the much older function of law. The evidence suggests that the mechanisms of quality assurance, through the need to document and measure quality, can also act as the mechanisms of legal exposure, providing evidence for both forms of regulation. The article explores the significance of this development in the context of debates over accountability and its role in shaping forms of democracy in public life. 


\section{Exposure: public-sector accountability and the law}

The bureaucracy of quality assurance is designed to regulate the actions of public-sector professionals, to hold their professions and institutions accountable to government and the public. Given the literature on unintended consequences of bureaucratic regimes, this is evidently a challenging aim on which to deliver. A key reason for this gap between policy and practice is the existence of what Lipsky (1980) famously coined street-level bureaucracy, via which forms of state-level bureaucracy must endeavour to deliver specific outcomes. The role of street-level bureaucrats as a variable in this delivery is significant, as their relative autonomy in the face of bureaucratic imperatives provides a space in which professional judgement and discretion are paramount. Just as significant in this context is their mediating function between the state and its public. As Lipsky put it, the 'essence of street-level bureaucracy is that they require people to make decisions about other people' (Lipsky, 1980: 161). They have the capacity to use discretion and professional judgement, and secondly they exercise these professional capacities in dealing with members of the public.

From a regulatory perspective, this space for autonomy and professional judgement, while a bulwark against forms of centralised decision making, becomes more problematic when placed in historical context. It is sometimes forgotten that it was concerns over professional decision-making that acted as a key driver of quality assurance mechanisms in the first place. The advent of these bureaucratic mechanisms in the United Kingdom was itself spurred on by a set of legal challenges to public-sector professions. Cases of medical malpractice and incompetence (in the health profession generally) led to the introduction of stronger systems of government surveillance in the National Health Service (NHS) (Harrison and McDonald, 2008: 44-45). Increasing concerns over professional incompetence in the NHS in the 1980s (including the famous Bristol Royal Infirmary incident) resulted, according to Travers (2007: 26), in the 'creation of a new inspectorate for the $\mathrm{NHS}^{\prime}$, a development that took place despite strong resistance from doctors to increased control from central government. Causer and Exworthy (1999: 87) point to a series of child abuse investigations in the 1980s which 'gave rise to the development of further reporting and monitoring procedures' in the field of social care. The period also witnessed more strident attacks on failing schools and 'bad' teachers - education was therefore not immune from the demands for quality and accountability across the public services (Gewirtz, 1997). Here, the values of discretion and judgement, so important to notions of professionalism, are as much sinners as sinned against.

This importance of liability exposure as a key driver of quality assurance in the public sector tends to be overshadowed by the discourse of new public management (Maesschalck, 2004: 466; Diefenbach, 2009: 906). While this discourse has played a significant role in shaping understandings of bureaucratic mechanisms (Morrell, 2009: 380 ), the perceived threat of unchecked professional ineptitude has also contributed to the growth of bureaucracy, a form of governance in which the concept of accountability as risk management takes centre stage. A good example of this conception in practice can be witnessed in clinical governance in the British NHS, which has been 'specifically politicised and driven as a means to warding against the risks clinicians have been perceived to pose' (Brown and Calnan, 2010: 14).

This type of risk illustrates the existence of forms of legal accountability alongside political ones, a context evident in the process of auditing, which is itself a political 
mechanism of accountability 'permeated if not dominated by legal risk' (Power, 1997: 139). Taking account of legal regulation comes with its own set of effects in the publicsector, professions, such as educators themselves increasingly having to grapple with the finer points of law. ${ }^{1}$

The existence of legal regulation alongside the rise of quality assurance mechanisms, suggests that Hupe and Hill are right when they state that 'accountability of street-level bureaucrats is essentially multiple' (Hupe and Hill, 2007: 279). Such a situation, however, begs the questions: What happens to the legitimacy of different regulatory functions? What occurs when they intersect? These are key questions, as forms of regulation tend to valorise certainty over ambiguity, and boundedness over permeability. What happens to this certainty in the real world of street-level bureaucracy?

\section{Method}

The purpose of the original study was to examine the impact of accountability mechanisms on the work of public-sector professionals in the UK, specifically how mechanisms such as audit and inspection impact on their relationships with the public. Included among the research subjects were nurses, social workers and teachers. In total, nine interviews and three focus groups were carried out, equally split between the three professions. The focus groups were organised once relevant themes had been identified in the individual interviews - the original set of interviews were guided by a set of questions concerning their current roles, the impact of accountability mechanisms on their roles, and their relationships with end-users. ${ }^{2}$

All interviews and focus groups were conducted in the same borough of the NorthWest of England. Given that three different professional groups were part of the study, it required different strategies to access the respondents. Participants were recruited via the organisations they worked for - school teachers were approached via the school principal, nurses were accessed via the hospital and social workers were recruited via the local council department in charge of the social care division. In order for access to be obtained to subjects that could provide adequate narratives around accountability and its consequences, more experienced personnel were requested to take part. This was the key factor when it came to the composition of the staff sample - these experienced staff could also point to any changes that had occurred to accountability regimes over the previous fifteen years or so. The data generated from the interviews and focus groups were analysed using an interpretive approach, where the researchers sought to explore some sensitive issues with the participants without setting restrictive parameters on what could be discussed. Although there is some previously published research in this general area, especially around unintended consequences, it was decided that, given the relative lack of research around accountability and public-sector professions, the data should generate their own core themes - hence the first set of interviews. Comparison across the three groups helped the researchers make judgements about trustworthiness, although it should be noted that the small sample size introduces a note of caution when it comes to generalisations about the findings. ${ }^{3}$

This article reports only on the consequences related to legal regulation, although of course these overlap with other aspects (see Murphy and Skillen, 2015, for a summary of findings related to time). Although the study was not framed around particular unintended consequences, some of these consequences came to the fore from an early point in the 
research. These included the role of law as a regulatory mechanism and the nature of trust in professional relationships.

The results of the study are detailed below - please note that real names have been replaced with pseudonyms.

\section{Findings: exposure and its consequences: litigation, risk and regulation}

The capacity of accountability mechanisms to perform as witness to professional life brings unavoidable pressure to bear on professional practice. The results of our research suggest that the location of street-level bureaucrats between state and street accountability has helped to create something of a legally ambiguous space within which street-level bureaucrats increasingly practice their professions. Squeezed between the need to control liability on the one hand and the threat of litigation on the other, this professional space has become home to an increasingly exposed professional life.

Such exposure inevitably transforms that professional life to some degree. The combination of political and legal exposure, alongside the presence of legal ambiguity, has created a set of professional anxieties among the staff surveyed in our research, anxieties that are themselves a product of risk, in particular the risk of evidential exposure. This risk anxiety on the part of professionals is to some extent based on historical evidence. As one of the teachers in the focus group stated, 'there is a lot of litigation in schools and I think there is even more which we just don't hear about. I can think of at least 10 cases of litigation in five years at my particular school' (Laura, teacher). The challenges of the modern classroom for teachers are increased when dealing with children with special educational needs:

I have a child with Fragile $X$ syndrome who throws things about, and again it's about how you manage that because you are worried that if she injures another child, will I get sued? If I restrain her, then will the parents sue me? (Brian, teacher)

This more cautious attitude to relationships has resulted in the development of a pro-active response to perceived threats, as witnessed among nurses:

You have a general feeling that if anything goes wrong, you will be sued. We also have to be more careful as the patients can quote you as saying that you have given them some information that perhaps was not the right information and the managers treat this very seriously. (Karen, nurse)

It is also the case that fear of litigation comes in different forms and at different intensities. As social workers directly deal with the legal system, their fears tend to lack the bedrock of confusion evident among the study's teachers and nurses. Nevertheless, concern over being sued appeared as part of their everyday working lives:

We have got to be prepared if they (police or lawyers) come to investigate and you have got to get it in to that system ... you could have it written down in your own notes but it needs to be put down on the computer ... because someone could look on the system and say that 'This child has not been seen for six months!' . . . I know that I have seen my children on a regular basis ... but if I had not had time to put it on the system then nobody else would ... this is a worry if it led to a legal case. (Bob, social worker) 
This fear of litigation is joined by a second order fear, the fear of risk. The need to control legal risk, a key part of the rationale for quality assurance mechanisms, could be said to have surfaced in the professional anxieties of those who have to police themselves on the front line of public services. The avoidance of risk itself becomes a risky activity, one that tends to frame patient interaction as an encounter that needs to be cautiously negotiated. While mechanisms of accountability such as audit may be a 'cosmetic process that hides real risk' (Power, 1997), they also contribute to a professional working culture that endeavours to avoid real risk.

A specific form of risk avoidance situated in the accountability/law nexus relates to direct physical contact with others. Although there are no specific accountability mechanisms that attach themselves to physical space, there was a particular concern that street accountability has affected their ability to both form meaningful relationships and to take appropriate professional action as they saw fit. As one of the teachers in the focus group put it, '10 years ago I would have probably picked her up and sat her down next to me and now I worry about doing that' (Sue, teacher). This sense of worry was also evident when talking to the nurses, specifically a worry about how a particular action might be legally interpreted: 'In the past if you had a confused patient you could link arms with them and go and get a cup of tea. That could be seen as restraining. You can't do this anymore' (Karen, nurse).

The fear of risk also surfaced with the potential for physical harm associated with particular professional environments. The danger of injury to members of the public is a particular concern for front-line professionals, especially those with a duty of care - and is arguably, a more significant rationale for litigation and for claims for compensation. Although litigation in the medical profession tends to grab the headlines, there is an increasing focus on the risks attached to physical behaviour in schools. The dangers of school trips, for example, has been a topic of debate in the UK, with some calling for the bureaucracy to be trimmed back so that schools and teachers can offer more activities outside of the school environment (Furedi and Bristow, 2012). One of the teachers in our study, however, indicates why some teachers prove reluctant to go on school trips. Brian, the teacher involved, took the school pupils to an indoor football tournament:

On my way back upstairs, I heard a scream and found a child who had cut her head on the railings. This worried me all night because if that parent took the risk assessment word for word I would be picking up my p45 in the morning. I didn't take the kids to any sports things after that. I stayed at school and did my marking instead.

Some caution in relation to litigation and the law is logical and justified. It could even be argued that a certain level of risk avoidance comes under the remit of a duty of care. But present in our research was a heightened level of professional anxiety. The same teacher reiterates this point when stating that, regarding the use of equipment, 'I don't think the risk assessments would be water tight with a lawyer who is trained in a specific field ... they would tear it apart.' Although Brian could never be sure what a lawyer would or could do in this circumstance, the fact that the threat was there contributed to the professional's sense of uncertainty in dealing with pupils and their physical environments. One of the nurses, Marie, echoed this sense of foreboding: 
I had a phone call from someone the other day who told me he was going to inform his solicitor because I didn't know what his mother had to drink on Friday and I wasn't there ... she had gone back to a nursing home and hospital staff weren't telling him anything about her situation.

Although the prevalence of such anxiety is significant, it is the impact of this professional anxiety on service that is arguably more worthy of attention. The quality of experience offered to patients, clients and pupils, according to our research, can sometimes suffer in the glare of legal regulation. One example of this is the case of behaviour management in schools, a contested but necessary function of education professionals. The encroachment of law into schools via equality legislation and health and safety law, alongside the threat of litigation, has made the management of children in school settings more problematic than previously. Behaviour management is affected by litigation 'because you are pussy-footing around them all the time and too frightened to discipline them properly'. (Sue, teacher)

Law encroaches on the quality of social work care in other ways. The threat of litigation in such a sensitive area of professional expertise means that, whether preparing for court or planning for complaints, more time is spent on paperwork than delivering care direct to the client:

\begin{abstract}
You are always aware of complaints procedures you have to follow in terms of what you have to write down and what you need to send. Ultimately it affects our supportive role because you spend a lot more time generating all this paper work, whereas perhaps a conversation on the phone could support them (foster carers) better than sending them reams of papers. (Alan, social worker)
\end{abstract}

\title{
The mechanisms of exposure: procedures and paper trails
}

Using steering mechanisms such as audit and inspection to regulate professional behaviour results in emphasis being placed on measured outcomes, which itself produces a culture of evidential exposure. The paper trail is a pivotal point around which accountability and law coalesce and reinforce each other. Paper trails count as evidence of accountability (or lack of), but the trail can also count, in different circumstances, as legal evidence. The evidential appetite of accountability mechanisms is one reason why so much time is devoted to them.

The creeping nature of exposure creates a nervous and uncertain professional climate - one of the senior nurses in the focus group put it bluntly when she stated that 'I am frightened my staff might miss something' (Sarah, nurse). Another suggested that:

We do fear litigation ... we have to check notes and as a manager I am very conscious of everything. It's ticking boxes and we are told not to write down too much, but I feel we should document everything just in case ... for example, things sometimes aren't dated and they wouldn't stand up in a court of law. (Claire, nurse)

Although they work more directly with the legal system, ensuring that the paper trail is in order is also a key concern for social workers. For social workers, the paper trail acts as both a buffer against litigation while also fuelling concerns as to its status, particularly when time does not allow staff to process the paper trail effectively: 
I do worry that if something happened to one of my children and somebody came in and seized the files, they would not be up to date ... I know where they are, they are written down but they are not on a system or in a file and that worries me because my time is so ad hoc I would prefer it if I had an hour to get it together to say 'there is the evidence' ... but you wouldn't have that hour... someone could come in and get the file to ask why something has happened to that child and that is a worry of mine. (Bob, social worker)

This tangible fear of being caught out by either their own forgetfulness or 'time compression' (Pollitt, 2009) is a result of a combination of different pressures being brought to bear on professional life. These pressures, even for social workers, cannot be considered the primary focus of the profession, but are rather secondary add-on features to an already complex set of routines. The fear associated with the law is as much a fear of exposure as it is a fear of failure.

\section{Discussion}

What do the findings tell us about the relationship between political and legal forms of regulation? They suggest that the evidential requirements of one form of regulation have the unintended effect of increasing exposure to another, somewhat more dormant, regulatory mechanism. Concerns over litigation means that street-level bureaucrats increasingly have to grapple with forms of street-level accountability: wedged in between state and street-level accountability, the likes of teachers, nurses and social workers are, in effect, embedded in a highly challenging regulatory environment.

What the findings also evidence is the conflicting effects of evidential exposure. The evidential requirements of accountability constitute a double-edged sword: evidence providing a platform for calling individuals and institutions to account, while also opening up professionals to liability exposure. This should not come as a surprise, however, given the legal history of current accountability arrangements. The findings indicate that the bureaucracy of quality assurance has not escaped its juridical history, never quite managing to shake off this facet of its genesis. A case could be made that accountability and its mechanisms, due to the emphasis on evidential exposure, are more and more occupying the ground between liability and litigation, reflecting Power's argument that 'legal risk enters the audit process as liability exposure' (Power, 1997: 139). Although Power was referring to the risk of the auditor, this statement could just as easily apply to public-sector professionals. The evidential nature of accountability mechanisms is fertile ground for exposure to legal risk.

What the bureaucracy of quality assurance contributes to professional life is a magnification of this legal risk, evidential exposure prone to highlighting incompetence and the dangers of unchecked professional discretion and judgement. A culture of mistrust and suspicion, alongside strategies of containment and professional obfuscation attached themselves to this form of bureaucracy early on, a set of values that have never quite been shaken off. Magnified legal risk inevitably helps to strengthen this culture, a culture in which 'watching your back' and 'covering your tracks' are paramount, and where emotions such as fear and doubt are never far from the surface.

The magnification of legal risk also has ramifications for goal conflict, an issue emphasised by Lipsky as a recurring theme in the field of street-level bureaucracy. For Lipsky (1980: 40), goal conflict arose in the context of goal ambiguity and the 
'unavailability of appropriate performance measures', with such goal conflicts having negative implications for the capacity of street-level bureaucrats to carry out their tasks. It could be argued that the issues illustrated here represent a new twist on Lipsky's concern over the impact of role expectations on goal conflict, in which goal ambiguity is joined here by the presence of evidential ambiguity. To some extent, he pre-empted this connection in his account of the police force (1980: 47). He viewed the police as the street-level bureaucrat most subject to conflicting goal expectations, because of their role in law enforcement, as a result of which the police may end up perceiving the public they come into contact with as 'hostile yet dependent' (1980: 47). While such a description might not yet apply to the perceptions of nurses, teachers and social workers, the evidence outlined here suggests a growing culture of 'self-policing' might be embedding itself in professional practices.

That said, while there are similarities, it should not be taken as given that accountability has equal effects across professions, or even within them. Other evidence suggests that there is a degree of heterogeneity attached to the experiences of accountability mechanisms, with other variables such as length of service coming into play. Exworthy and Halford (1999: 13), for example, while identifying similarities, were also keen in their study to emphasise key differences between them - history, structure, timing and degree of change, occupational status - any of which have a bearing on the degree to which accountability helps or hinders professional practice (see also Travers, 2007).

This meshing of law and accountability points to another difficulty when assessing the impact of bureaucracy on professional life. Given the state of confusion evidenced in this article, it is reasonable to ask the question: where does accountability end and what Habermas (1987: 357) calls 'juridification' begin? That is, how much of what professionals see as a product of a rampant audit culture is more of a manifestation of formal law strengthening its hold on professional practice? (see also Baxter, 2011: 55-56). This is a significant question, as the ability to provide some kind of an answer could tell us more about the reaches and limits of accountability and also the role of legislation in mediating professional relationships.

\section{Conclusion}

The research detailed in this article set out to examine the impact of accountability mechanisms on public-sector workers and their capacity to fulfil their professional duties. The research focused on how law mediates the relationship between accountability demands and professional work of street-level bureaucrats. The findings of the study suggest that the enmeshing of legal and political regulation has its own sets of consequences. These consequences revolve around the entanglement of measurement and evidence at the street level, increasing the levels of professional uncertainty, liability exposure and regulatory complexity.

This article, then, is a contribution to research exploring accountability and its consequences, adding liability exposure to an ever-growing list of side effects of the bureaucracy of quality assurance. The emphasis on legal regulation as a mediating factor, however, should be seen as a novel contribution to this specialised sub-field, given that this factor has been relatively neglected in the literature. The article also makes a strong contribution to the developing field of research exploring professional discretion more 
generally (e.g., Tummers and Bekkers, 2014), offering what Brodkin (2008: 337) calls a 'street-level approach to accountability' which has the potential to highlight aspects of policy delivery 'that other analytic strategies do not capture' (Brodkin, 2008: 327).

Admittedly, these findings are based on a small sample of participants and spread across three professions, so the argument presented here should be viewed as one needing further testing and refinement. Whilst the research focuses on the similarities between forms of street-level bureaucracy, further research is necessary to ascertain the extent of risk magnification within and across professions. There are numerous other public-sector professional groupings, including the police, but also the fire service, probation and prison officers, care workers of various types, that could be researched in a similar fashion and who might deliver a different set of findings.

That said, the three professions covered in this study have in common a strong ethic of care towards their public, whether they be pupils, patients or clients. Adopting a streetlevel approach to these kinds of professional groups can help us understand the limits of regulation generally. What the findings indicate is that just as there needs to be some balance between professional autonomy and bureaucratic control, so there also needs to be a balance between exposure and protection for street-level bureaucrats. It could be argued that the presence of this magnified legal risk, for all its faults, can act as a check on the more malign aspects of public-sector professionalism - inefficiency, insularity and self-interestedness. Proponents could point to the cases of incompetence and neglect cited earlier in this article as justification enough for a work culture that keeps professionals 'on their toes' and fearful of public response. If the findings of this research are anything to go by, however, the evidential exposure may help to diminish the quality of service delivery rather than enhance it. Relations of trust and respect, surely key components of any public interface, are never adequately served by a culture of suspicion and avoidance.

There are therefore potential consequences for end-users of this accountability/law nexus which demand further attention. Even if only indicated here, the spread of a 'hostile yet dependent' relationship between street-level bureaucrats and the public would cancel out whatever benefits might accrue from further accountability-led public-sector reform. The need to 'cover your tracks' can potentially take precedence over a duty of care to end-users, whether they be patients, clients or pupils. Just as potentially damaging is the likelihood that such approaches to their job might become routine over time, a development that Lipsky viewed as a barrier to professional change - i.e., patterns of practice that are 'not easily abandoned or changed because they are experienced by workers and outside observers as virtual job requirements. People do not readily give up survival mechanisms' (Lipsky, 1980: 87). Professional practice at the street level, in both its more progressive and conservative forms, is not easy to shift.

Such a street-level approach can also help us to acknowledge the limitations of a 'statist' perspective to governance and regulation, in that the nuance of the 'street level' can easily be overshadowed. As Ball put it in relation to education policy (1994: 10-11), 'policies are crude and simple. Practice is sophisticated, complex and unstable.' The professional practice detailed in this study reveals a front line that embodies a set of conflicting imperatives, where tension is arguably the norm rather than the exception. The concerns of the professionals illustrate the unpredictable and fragile nature of dealing with other people in a formal professional context, which is also simultaneously a context of care, obligation and rights. 
These policy and theory limitations may have something to do with what Beetham (1996: 48) calls a 'serious limitation' of theories of bureaucracy generally - i.e., that they 'treat bureaucracy in isolation, as a self-sufficient object of study, in abstraction from any social or historical context, or any larger theory of society or history'. The street-level perspective provided in this study addresses some of these contextual failings, and points to the need for a more elaborate study of the state and its capacity to govern public-sector professionals, a set of street-level bureaucrats with an ever-increasing set of accountability demands.

\section{Notes}

1 Research in the field of education for example indicates that legislative changes do not always translate neatly into the classroom - introducing the notion of reasonable adjustment into the school contexts resulted in teachers and school administrators having to make decisions based on little experience of legal interpretation (Riddell and Weedon, 2006). Other research suggests that the fear of malpractice litigation can impact on teacher performance in the classroom (Reed et al., 2008). These kinds of outcomes may not have been intended or desirable, but from the vantage point of professional practice are understandable.

2 The topics covered in the interviews included: the prevalence of accountability mechanisms in their institutions; the relative importance of different types of quality assurance mechanism, such as audit; the frequency of these quality assurance mechanisms and the extent to which they impinged on their daily routines; the impact of accountability on their professional practice; examples of accountability in action; their perception of the value of these quality assurance mechanisms; the impact of the accountability on their relationships with their clients. Once the interviews were completed, it was evident that issues such as time and the role of law were significant themes that had been highlighted in discussions of the original interview themes - these then helped to guide the questioning in the focus groups.

3 The small sample size and the fact that participants were not randomly chosen but rather requested from a larger pool of professionals can be considered a drawback of the current research. This is acknowledged by the researchers, although it should also be pointed out that this is balanced by the strengths of an approach that draws comparisons across professional sectors. Such forms of research and their findings can act as a springboard for future large-scale studies of similar issues across professions.

\section{References}

Allsop, J. and Jones, K. (2008) 'Withering the citizen, managing the consumer: complaints in healthcare settings', Social Policy and Society, 7, 2, 233-43.

Ball, S. (1994) Education Reform: A Critical and Post-Structuralist Approach, Buckingham: Open University Press.

Barberis, P. (1998) 'The new public management and a new accountability', Public Administration, 76, 451-70.

Baxter, H. (2011) Habermas: The Discourse Theory of Law and Democracy, Stanford, CA: Stanford University Press.

Beetham, D. (1996) Bureaucracy, 2nd edn, Buckingham: Open University Press.

Bovens, M. (2010) 'Two concepts of accountability: accountability as a virtue and as a mechanism', West European Politics, 33, 5, 946-67.

Bundred, S. (2006) 'The future of regulation in the public sector', Public Money and Management, 26, 3, $181-8$.

Brodkin, E. (2008) 'Accountability in street-level organizations', International Journal of Public Administration, 31, 3, 317-36. 
Brown, P. and Calnan, M. (2010) 'The risks of managing uncertainty: the limitations of governance and choice, and the potential for trust', Social Policy and Society, 9, 1, 13-24.

Causer, G. and Exworthy, M. (1999) 'Professionals as managers across the public sector', in M. Exworthy and S. Halford (eds.), Professionals and the New Managerialism in the Public Sector, Buckingham: Open University Press, 83-101.

Diefenbach, T. (2009) 'New public management in public sector organizations: the dark sides of managerialist "enlightenment"', Public Administration, 87, 4, 892-909.

Exworthy, M. and Halford, S. (eds.) (1999) Professionals and the New Managerialism in the Public Sector, Buckingham: Open University Press.

Furedi, F. and Bristow, J. (2012) The Social Cost of Litigation, London: Centre for Policy Studies.

Gewirtz, S. (1997) 'Post-welfarism and the reconstruction of teachers' work in the UK', Journal of Education Policy, 12, 4, 217-31.

Habermas, J. (1987) The Theory of Communicative Action, Vol. 2: Lifeworld and System: A Critique of Functionalist Reason, Boston, MA: Beacon Press.

Harrison, S. and McDonald, R. (2008) The Politics of Healthcare in Britain, London: Sage.

Hupe, P. and Hill, M. (2007) 'Street level bureaucracy and public accountability', Public Administration, $85,2,279-99$.

James, O. (2005) 'The rise of regulation of the public sector in the United Kingdom', Sociologie du Travail, 47, 323-39.

Liff, R. (2014) 'Unintended consequences of NPM drive the "bureaucracy"', International Journal of Public Administration, 37, 8, 474-83.

Lipsky, M. (1980) Street-level Bureaucracy: Dilemmas of the Individual in Public Services, New York: Russell Sage Foundation.

Maesschalck, J. (2004) 'The impact of new public management reforms on public servant's ethics: towards a theory', Public Administration, 82, 2, 465-89.

Mendez, C. and Bachtler, J. (2011) 'Administrative reform and unintended consequences: an assessment of the EU cohesion policy "audit explosion"', Journal of European Public Policy, 18, 5, 746-65.

Morrell, K. (2009) 'Governance and the public good', Public Administration, 87, 3, 538-56.

Mulgan, R. (2000) 'Accountability: an ever expanding concept?', Public Administration, 78, 3, 555-73.

Murphy, M. and Skillen, P. (2015) 'The politics of time on the front line: street level bureaucracy, professional judgement and public accountability', International Journal of Public Administration, 38, 9, 632-41.

Ossege, C. (2012) 'Accountability: are we better off without it?', Public Management Review, 14, 5, 585-607.

Papadopoulos, Y. (2010) 'Accountability and multi-level governance: more accountability, less democracy?', West European Politics, 33, 5, 1030-49.

Parker, C. (2008) 'The pluralisation of regulation', Theoretical Inquiries in Law, 9, 2, 349-69.

Pollitt, C. (2009) 'Bureaucracies remember, post-bureaucratic organizations forget?', Public Administration, 87, 2, 198-218.

Power, M. (1997) Audit Cultures: Rituals of Verification, Oxford: Oxford University Press.

Reed, D., Windish, D., Levin, R., Kravet, S., Wolfe, L. and Wright, S. (2008) 'Do fears of malpractice litigation influence teaching behaviors?', Teaching and Learning in Medicine, 20, 3, 205-11.

Riddell, S. and Weedon, S. (2006) 'What counts as a reasonable adjustment? Dyslexic students and the concept of fair assessment', International Studies in Sociology of Education, 16, 1, 57-73.

Travers, M. (2007) The New Bureaucracy: Quality Assurance and its Critics, Bristol: Policy Press.

Tummers, L. and Bekkers, V. (2014) 'Policy implementation, street-level bureaucracy, and the importance of discretion', Public Management Review, 16, 4, 527-47. 